\title{
Evaluación de la calidad del agua de los ríos de la ciudad de Cuenca, Ecuador
}

\section{Water quality assessment of the rivers of Cuenca city in Ecuador}

\author{
Guillermina Pauta $^{1}{ }^{(\mathbb{D})}$, María Velasco ${ }^{1}$, Daniela Gutiérrez $z^{1}$, Gabriela Vázquez ${ }^{1}{ }^{(\mathbb{D}}$, Santiago \\ Rivera $^{2}$, Óscar Morales ${ }^{2}$, Andrea Abril ${ }^{1}$ iD \\ ${ }^{1}$ Laboratorio de Sanitaria, Departamento de Ingeniería Civil, Universidad de Cuenca, Cuenca, Ecuador. \\ 2 Integrated Water Quality Management Project, VLIR, Universidad de Cuenca, Cuenca, Ecuador. \\ Autor para correspondencia: guillermina.pauta@ucuenca.edu.ec \\ Fecha de recepción: 10 de abril de 2019 - Fecha de aceptación: 12 de diciembre de 2019
}

\section{RESUMEN}

Se evaluó la calidad del agua de los ríos Tarqui, Yanuncay, Machángara y Tomebamba, afluentes del río Paute. En línea con la necesidad de incorporar nuevos enfoques en la vigilancia de la calidad del agua, este estudio aplicó el ampliamente conocido Water Quality Index (QWI) pero, en lugar de utilizar los nueve parámetros originalmente requeridos por el método, utilizamos 18 parámetros fisicoquímicos y microbiológicos. Para cada río, se llevaron a cabo nueve campañas de monitoreo, cubriendo períodos hidrológicos representativos y midiendo descargas de flujo. Los resultados muestran que, en general, en las áreas de captación de los ríos, el recurso hídrico es adecuado para casi todo tipo de uso, pero gradualmente, a medida que avanza aguas abajo, la calidad disminuye debido a las descargas de aguas residuales sanitarias, industriales y a factores naturales como escorrentía o sedimentos por erosión. La condición más crítica de calidad de las aguas evaluadas se presentó durante las condiciones de sequía, principalmente debido a la disminución del oxígeno disuelto y al aumento de la temperatura, la salinidad, la materia orgánica y las bacterias coliformes. Por otro lado, durante los períodos lluviosos, los parámetros indicadores de una disminución en la calidad del agua fueron el color, la turbidez, y el contenido de nutrientes como fósforo y nitrógeno. En general, los ríos tienen mejor calidad para condiciones de flujo medio, que prevalecen durante la mayor parte del año. Los presentes resultados se analizaron de acuerdo con los objetivos de calidad establecidos en estudios anteriores, permitiendo una evaluación cualitativa del sistema de intercepción y tratamiento de aguas residuales de la ciudad de Cuenca, Ecuador.

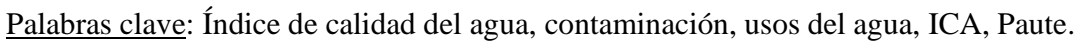

\begin{abstract}
The water quality of the Tarqui, Yanuncay, Machángara and Tomebamba rivers, tributaries of the Paute river was evaluated. Due to the need to incorporate new approaches in the water quality monitoring, this study applied the widely known water quality index (WQI) but, instead of using the 9 parameters originally required by the method, we used 18 physicochemical and microbiological parameters. For each river, nine monitoring campaigns were carried out, covering representative hydrological periods and measuring flow discharges. The results show that, in general, in the areas of river catchment, the water resource is suitable for almost all types of use, but gradually, as it progresses downstream, the quality decreases due to sanitary or industrial wastewater and to natural factors such as runoff or erosion sediments. The most critical condition of the evaluated river's water quality was presented during drought conditions, mainly due to the decrease in dissolved oxygen and the increase in temperature, salinity, organic matter and coliform bacteria. On the other hand, during rainy periods, parameters indicating a decrease of water quality were color, turbidity, and nutrient content such as phosphorus and nitrogen. In general, rivers have better quality for medium flow conditions, which prevail during most of the year. The present results were analyzed in accordance with the quality objectives established in previous studies, allowing a qualitative evaluation of the wastewater interception and treatment system of the city of Cuenca, Ecuador.
\end{abstract}

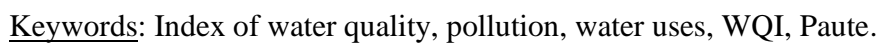

\section{INTRODUCCIÓN}

Los cuatro ríos que discurren por la ciudad de Cuenca (Tarqui, Yanuncay, Machángara y Tomebamba), capital de la provincia del Azuay, constituyen una arteria vital y de desarrollo de esta población. Además, estos ríos son afluentes importantes del río Paute, en cuya cuenca de captación inferior opera el proyecto hidroeléctrico Paute, de ámbito de influencia nacional. En este sentido, 
información actualizada y periódica sobre la calidad de las aguas de los mencionados recursos hídricos, constituye una herramienta fundamental para la toma de decisiones en términos del buen uso y conservación de estos recursos.

Aun cuando la ciudad de Cuenca dispone de un sistema de depuración en base a lagunas de estabilización, operativo desde el año 1998, una de las principales formas de contaminación de las aguas de los ríos que atraviesan esta ciudad, ocurre por la disposición final, por dilución, de los sistemas de alcantarillado de varios de sus numerosos asentamientos menores como cabeceras parroquiales, caseríos y una amplia población dispersa, además de vertidos ilegales, que no se encuentran conectados al sistema de colectores marginales del sistema de depuración de aguas. Este tipo de contaminación, por aguas residuales domésticas y/o industriales, limitan los usos del recurso tanto para fines agrícolas, así como para abastecimiento de agua.

Los suministros de agua generalmente provienen de dos fuentes principales: aguas superficiales y subterráneas, procedencias totalmente interrelacionadas; como el agua se mueve a través del sistema de vías superficiales y subterráneas su calidad se altera frecuentemente en forma significativa, así el agua que sale de la zona de captación será diferente del agua que ha caído en ella como precipitación; por lo que el aporte continuo de contaminación a los ríos de la ciudad, no afecta solamente la calidad de los cuerpos receptores, sino también de los suministros subterráneos.

El agua destinada a consumo humano debe cumplir requisitos de calidad, los mismos que cada vez son más difíciles de alcanzar, debido a la presencia de sustancias de muy diverso origen en las corrientes receptoras, lo que exige la implementación de tratamientos costosos y difíciles de aplicar sobre todo en comunidades con bajo nivel técnico y escasos recursos económicos; así, la selección cuidadosa de la fuente de abastecimiento, como la protección de los ríos, son temas relevantes, mientras más limpia sea el agua de la fuente o agua cruda, más barata será el agua tratada y más sana para beber.

La calidad del agua tal como la encontramos en la naturaleza depende fundamentalmente de las características de la cuenca hidrográfica, especialmente de los suelos y de la geología, pero la actividad antropológica es la más influyente en la polución de los ríos; la intensa actividad agrícola, ganadera y la urbanización presentes a lo largo de las subcuencas de los ríos estudiados, constituyen la principal fuente de contaminación, por lo que disponer de agua para bebida con requisitos de calidad es muy difícil para algunos sectores de la población que utilizan estas fuentes de abastecimiento.

Los ríos tienen características propias de calidad, y ésta es variable con el tiempo (Rauch et al., 1998). La calidad en un río, se refiere a la naturaleza y concentración de las sustancias que pueden estar presentes en un momento determinado; algunas son de origen natural, pero otras son introducidas por el hombre al utilizar el cuerpo receptor como el lugar idóneo para arrojar residuos (Carretero \& Pozo-Rodriguez, 2007); los contaminantes en general pueden ser conservativos y no conservativos (Tebbutt, 1998a); es útil la siguiente clasificación: i) compuestos tóxicos, que causan inhibición y destrucción de la actividad biológica, tales como: metales pesados, hidrocarburos aromáticos policíclicos, plaguicidas, etc.; algunos de éstos hoy reciben el nombre de compuestos refractarios, porque resisten los procesos convencionales de tratamiento (Metcalf \& Eddy, Inc., 2003); ii) materiales que afectan el balance de oxígeno en el agua, como: materia orgánica, agentes químicos reductores, grasas, aceites y detergentes, etc.; iii) sólidos inertes en suspensión o disueltos, que a elevadas concentraciones limitan los usos del agua. Sin embargo, el río como todo cuerpo acuático posee una capacidad de autodepuración a través de varios mecanismos como: el transporte y depósito (sedimentación) de materiales contaminantes, posiblemente alentada por la floculación bacteriana; reacciones químicas y bioquímicas que se realizan en la masa del agua y en la superficie de la materia suspendida $(\mathrm{pH}$, sorción, ácido-base, redox, complejación, catabolismo, asimilación-desasimilación, etc.); intercambio de compuestos volátiles entre la masa de agua y la atmósfera (pérdida o entrada de oxígeno, anhídrido carbónico, nitrógeno, etc.); reacciones redox en los sedimentos, y finalmente la descomposición bacteriana debida a un ambiente generalmente inhóspito para bacterias entéricas y patógenas (Catalán-La Fuente \& Catalán-Alonso, 1992). Todos estos mecanismos confieren al río la facultad de incorporar en sus circuitos biológicos estos materiales y energía extraños, recuperando su funcionalidad.

En el agua existen dos tipos de interacciones solutodisolvente: la inducida por aquellos solutos que "refuerzan" la estructura del agua, y la producida por solutos que la "rompen" o la distorsionan drásticamente. Los primeros suelen ser compuestos no iónicos como los hidrocarburos y en general, moléculas no polares, las cuales se sitúan en el límite del enlace del hidrógeno, reforzando los puentes de hidrógeno entre las moléculas de agua; los otros son sustancias de carácter polar, provocan en el líquido reacciones complejas, por interacciones eléctricas que modifican la estructura tridimensional "normal" del agua (Marín-Galvín, 2019).

La presencia o ausencia de todas estas sustancias y en un momento dado, definen la calidad del agua; la información que proporcionan los análisis para referirse a la calidad, normalmente se evalúa empleando un índice (WQI o ICA) el cual, basado en un determinado modelo de cálculo, permite resumir una gran cantidad de información en un sólo número que, comparado luego con una escala preestablecida, define la calidad del recurso y por la tanto los usos del mismo (Torres, Cruz, Patiño, Escobar, \& Pérez, 2010).

La conformación de un ICA asocia parámetros de interés dependiendo del objetivo de la evaluación y de la zona de estudio; estos índices constituyen herramientas de mucha utilidad para los técnicos, los expertos, las autoridades y/o organismos encargados del manejo y control del recurso. Literatura especializada que informa sobre los índices de calidad más usados a nivel mundial, las bases para su conceptualización y su evolución en el tiempo son el Oregon Water Quality Index (Cude, 2001) o el propuesto por el Departamento de Calidad Ambiental de Idaho (DEQ State Office, s. f.).

La mayoría de autores recomiendan incluir en el índice, parámetros de las cinco categorías consideradas como las más importantes: i) nivel de oxígeno, por su importancia en la capacidad de autodepuración de las corrientes; ii) eutrofización, por constituir un problema del ecosistema con efectos en los usos del agua; iii) aspectos de salud, por el riesgo sanitario; iv) características físicas, de importancia en la estética del agua; y v) sustancias 
disueltas, relacionadas con la presencia de iones (SierraRamírez, 2011).

Los ríos objeto de estudio en este trabajo, ya han sido evaluados por la Empresa Pública de Telecomunicaciones, Agua Potable, Alcantarillado y Saneamiento de Cuenca (ETAPA EP), a través del índice WQI desarrollado por la Fundación Nacional de Saneamiento (NSF por sus siglas en inglés) de los Estados Unidos de América, basado en nueve parámetros (Dinius, 1987): oxígeno disuelto, turbiedad, sólidos totales, coliformes fecales, variación de temperatura, $\mathrm{pH}$, nitratos, fosfatos, y DBO5, y define cinco rangos de calidad; la presente investigación por su parte evalúa la calidad del agua con un índice que si bien está basado en el WQI original, considera 18 parámetros fisicoquímicos y microbiológicos, la metodología utilizada permite detectar el tiempo en el que ocurrió la contaminación e incluye parámetros relacionados con la hidrogeoquímica del agua, aspectos importantes en la calidad del recurso y no considerados en el índice WQI originalmente propuesto por la NSF. Variaciones del método propuesto por la NSF han sido utilizadas ya en estudios previos como el de (León-Vizcaíno, 1992) o en documentos técnicos de la Secretaría de Medio Ambiente y Recursos Naturales de México (SEMARNAT, s. f.).

Finalmente, se debe considerar que un río es un reactor permanentemente mezclado y los aspectos que controlan la calidad del agua y explican su dinámica son: el paisaje de la cuenca, los factores constitutivos de un río, y el agua misma (Catalán-La Fuente \& Catalán-Alonso, 1992). Una evaluación integral requiere atención a todos estos factores. Conservar la calidad del agua de los ríos es de vital importancia pues de su calidad depende su uso; pero el aspecto que hoy prima es el efecto nocivo sobre la salud humana y el medio ambiente, debido a sustancias tóxicas que el río puede arrastrar (e.g., Jones, 2013).

El objetivo del presente trabajo fue determinar, mediante el índice de calidad ICA, el estado de los ríos: Tarqui, Yanuncay, Machángara y Tomebamba, y evaluar la variación de la calidad del agua frente a las diversas posibilidades de contaminación causada por la descarga de agua residual sanitaria y/o industrial. Además, se definirán los usos que pueden asignarse al recurso en las actuales condiciones y especificar metas de calidad para objetivos específicos.

\section{MATERIALES Y MÉTODOS}

\subsection{Descripción de la zona de estudio}

El área de estudio corresponde a cuatro subcuencas del río Paute, ubicadas en el sur del Ecuador, Provincia del Azuay; dentro de las mismas se encuentra el cantón Cuenca cuya población al año 2010 fue de 505,585 habitantes (INEC, 2010) y para el año 2019 según proyecciones del INEC existirían 625,775 habitantes. Las subcuencas de los ríos Yanuncay $\left(419 \mathrm{~km}^{2}\right)$, Tomebamba $\left(380 \mathrm{~km}^{2}\right)$ y Machángara $\left(325 \mathrm{~km}^{2}\right)$ nacen en el Parque Nacional Cajas, mientras que el río Tarqui $\left(476 \mathrm{~km}^{2}\right)$ nace en los páramos de Cumbe y de la parte alta de la Victoria del Portete (Fig. 1).

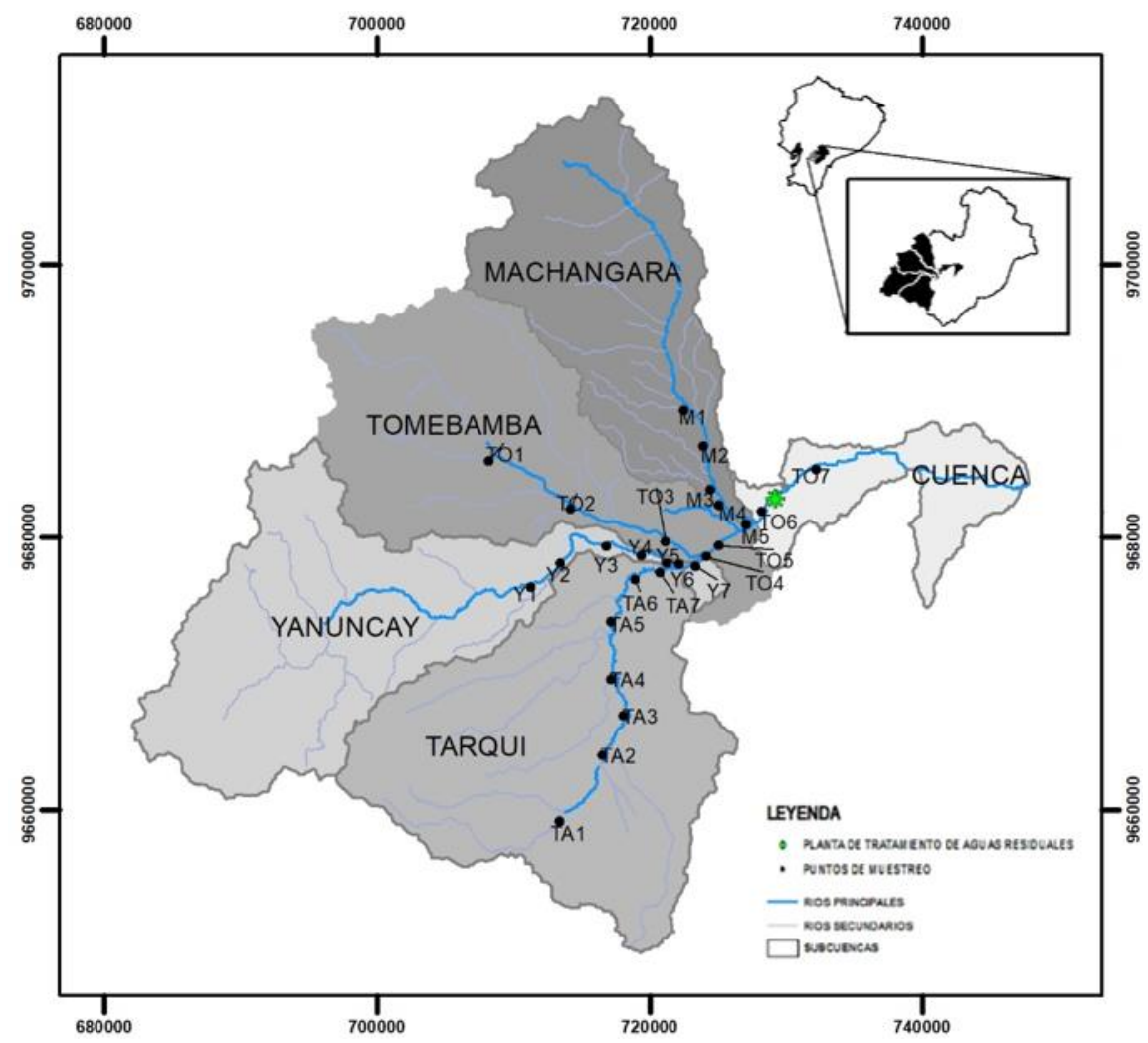

Figura 1. Área de estudio y estaciones de monitoreo en las subcuencas evaluadas. Los acrónimos se definen en la Tabla 1. 
Todos los ríos atraviesan la ciudad de Cuenca en sentido Este-Oeste; esta ciudad cuenta con una amplia red de interceptores marginales en los cuatro ríos; sin embargo, la cobertura en servicios de alcantarillado no es del $100 \%$, existiendo a la fecha de monitoreo, varias descargas que no han sido interceptadas.

\subsection{Metodología del monitoreo}

Se diseñó un programa de monitoreo de nueve campañas para cada río, con estaciones estratégicamente ubicadas desde la zona alta hasta el final de su recorrido como se muestran en la Figura 1. Los sitios de monitoreo fueron establecidos procurando la disponibilidad de una estructura transversal al río que permita la medición del caudal y la influencia de los afluentes importantes a cada río, como cuerpos de agua natural o la descarga de la PTAR. La Tabla 1 indica las denominaciones de cada sitio de muestreo en los diferentes ríos.

Tabla 1. Referencia de los sitios de monitoreo en los cuatro ríos de estudio.

\begin{tabular}{|c|c|c|}
\hline Subcuenca & Código & Referencia \\
\hline \multirow[t]{7}{*}{ Tarqui } & TA1 & Portete \\
\hline & TA2 & DJ Cumbe \\
\hline & TA3 & Tarqui \\
\hline & TA4 & Zona Franca \\
\hline & TA5 & DJ Zhucay \\
\hline & TA6 & Parque Inclusivo \\
\hline & TA7 & AJ Yanuncay \\
\hline \multirow[t]{7}{*}{ Yanuncay } & $\mathrm{Y} 1$ & Dispensario Barabón \\
\hline & $\mathrm{Y} 2$ & Inmaculada de Barabón \\
\hline & Y3 & San Joaquín \\
\hline & Y4 & Avenida Loja \\
\hline & Y5 & Tres Puentes \\
\hline & Y6 & UDA \\
\hline & Y7 & Parque el Paraíso \\
\hline \multirow[t]{7}{*}{ Tomebamba } & TO1 & Llaviuco \\
\hline & TO2 & Sayausí \\
\hline & TO3 & Puente del Vado \\
\hline & TO4 & Empresa Eléctrica \\
\hline & TO5 & AJ Quebrada Milchichig \\
\hline & TO6 & AD PTAR de Cuenca \\
\hline & TO7 & Challuabamba \\
\hline \multirow[t]{5}{*}{ Machángara } & M1 & Chiquintad \\
\hline & M2 & Ochoa León \\
\hline & M3 & Feria de Ganado \\
\hline & M4 & Parque Industrial \\
\hline & M5 & AJ Tomebamba \\
\hline
\end{tabular}

Las estaciones TO6 y TO7, están ubicadas en el río Cuenca, arteria hidrográfica que se conforma a partir de la unión del río Tomebamba con el Machángara. Cada río fue evaluado durante un año a partir del 2012 y concluyó en el 2015, considerando períodos hidrológicos representativos. En cada estación se midió el caudal y se consideró los tiempos de paso entre las estaciones. Las mediciones de caudal se realizaron en base a las recomendaciones de (Te-Chow, Madiment, \& Mays, 1994): se fraccionó la sección del río en intervalos regulares (aprox. $3 \mathrm{~m}$ ), dentro de cada intervalo se midió la profundidad y con un correntómetro o molinete se determinó la velocidad en cada tramo. Considerando la ecuación de la continuidad se calculó el caudal parcial por cada sección, multiplicando el área de esta por la velocidad medida y el caudal total se calcula con la suma de los caudales parciales. Para profundidades del río inferiores a los $70 \mathrm{~cm}$ se realizó una sola medición, al $60 \%$ de profundidad, y cuando superaba $l o s \quad 70 \mathrm{~cm}$ se realizaron dos mediciones, al $20 \%$ y al $80 \%$ de profundidad, y se determinó un promedio de dichas velocidades para esa sección.

Las muestras recolectadas para los análisis fueron compuestas a volúmenes fijos, y se captaron en tres zonas de la sección del río (margen izquierda, derecha y centro); se conservaron a $4^{\circ} \mathrm{C}$ durante su traslado, y parámetros como el oxígeno disuelto y la temperatura fueron medidos in situ.

\subsection{Determinación del Índice de Calidad de Agua (ICA)}

El modelo utilizado para la evaluación del índice ICA maneja 18 parámetros (Tabla 2; SEMARNAT, s. f.) indicativos de aspectos importantes del agua como: la estética, presencia de nutrientes, materia orgánica, disponibilidad de oxígeno y contaminación bacteriana. El cálculo del ICA se realiza aplicando un método aditivo, mediante la Ecuación 1. En la fórmula, cada parámetro tiene un peso relativo de acuerdo con su importancia, como se indica en la Tabla 2.

$$
I C A=\frac{\sum_{i=1}^{n} I_{i} W_{i}}{\sum_{i=1}^{n} W_{i}}
$$

en donde: ICA=índice de calidad del agua global; $I_{i}=$ índice de calidad $i$-ésimo parámetro; $W_{i}=$ coeficiente de ponderación del $i$-ésimo parámetro; $n=$ número total de parámetros.

Las ecuaciones definidas para el índice de calidad individual de cada uno de los 18 parámetros son funciones de transformación, mediante las cuales las unidades heterogéneas de expresión de cada parámetro son convertidas en unidades homogéneas de calidad de agua (Chang-Gómez, 2009). Los métodos usados para la determinación de los parámetros referidos son los establecidos por el Standard Methods para la evaluación del agua y aguas residuales (American Public Health Association, 2005). El modelo de cálculo del ICA permite, en ausencia de un dato, considerar un coeficiente de ponderación nulo para el parámetro al que corresponda en la evaluación del ICA.

El resultado del cálculo realizado con las consideraciones citadas anteriormente corresponde a un valor entre $0 \mathrm{y}$ 100. La clasificación se realiza en 5 grupos con un criterio de calidad correspondiente. En la Tabla 3 se muestra el criterio para la clasificación de la calidad del agua. Los usos descritos en dicha Tabla son compatibles con los establecidos en la normativa ecuatoriana, según el Texto Unificado de la Legislación Secundaria del Ministerio del Ambiente (Ministerio del Ambiente, 2015); por lo tanto, los criterios de calidad obtenidos con el índice ICA son 
aplicables a los usos establecidos en la normativa ecuatoriana mencionada.

\subsection{Clasificación de los monitoreos de acuerdo con el caudal}

Con el objetivo de especificar el régimen de caudal de toda una campaña de monitoreo, se realizó un análisis por estación determinando los quintiles para cada grupo de datos. Al quintil $1(<20 \%)$ se lo cataloga como un caudal bajo, al quintil $5(>80 \%)$ se cataloga como un caudal alto, mientras que para los quintiles 2,3 y $4(20 \%<\mathrm{Q}<80 \%)$, como caudal medio.

Tabla 2. Lista de parámetros y coeficiente de ponderación para el cálculo del ICA, según SEMARNAT (s. f.).

\begin{tabular}{lc}
\hline \multicolumn{1}{c}{ Parámetro } & $\begin{array}{c}\text { Coeficiente de } \\
\text { ponderación }\end{array}$ \\
\hline $\mathrm{pH}$ & 1.0 \\
Color & 1.0 \\
Turbiedad & 0.5 \\
Grasas y Aceites & 2.0 \\
Sólidos Suspendidos & 1.0 \\
Sólidos Disueltos & 0.5 \\
Conductividad Eléctrica & 2.0 \\
Alcalinidad & 1.0 \\
Dureza Total & 1.0 \\
Nitrógeno de Nitratos & 2.0 \\
Nitrógeno Amoniacal & 2.0 \\
Fosfatos Totales & 2.0 \\
Cloruros & 0.5 \\
Oxígeno Disuelto & 5.0 \\
DBO (5 días) & 5.0 \\
Coliformes Totales & 3.0 \\
Coliformes Fecales & 4.0 \\
Sustancias activas al azúl de metileno & 3.0 \\
\hline
\end{tabular}

\section{RESULTADOS}

\subsection{Análisis de caudales y variación temporal de la calidad del agua}

La Figura 2 muestra la representatividad del período de muestreo; de los nueve monitoreos realizados en cada río, cinco son catalogados como de caudal medio (M), dos de caudal alto (A) y dos de caudal bajo (B), variación similar a la que presenta el caudal de los ríos durante el año, con máximos y mínimos, predominando el caudal medio.

En cada estación, y en todos los ríos, la calidad está relacionada con el período estacional (Fig. 3). En el río Tarqui la estación con menor variabilidad de la calidad fue Zona Franca TA4 con una desviación standard $\sigma$ en sus ICAs de 2.76; mientras que la de mayor variabilidad fue Parque Inclusivo TA6 $(\sigma=5.18)$, debido a la intensa actividad recreativa y poco contralada de la zona, sobre todo durante los fines de semana. Para el Yanuncay, la estación de menor variabilidad fue Parque El Paraíso Y7 $(\sigma=3.27)$; esta estación es antes de la junta con el río Tomebamba; en cambio, la estación de mayor variabilidad fue Tres Puentes Y5 $(\sigma=6.74)$, debido a descargas puntuales e intermitentes de agua residual doméstica no interceptada procedente de la urbanización. En el río
Machángara la estación de menor variabilidad es Parque Industrial M4 $(\sigma=2.13)$ y la de mayor variabilidad fue Feria de Ganado M3 ( $\sigma=3.78$ ), debido a la influencia de esta actividad intermitente de feria que se realiza los jueves; sin embargo, la variación de la calidad en todas las estaciones es muy pequeña, lo que indica que no hay influencia significativa del período climatológico, debido a la regulación del caudal efectuada aguas arriba para el aprovechamiento energético. En el río Tomebamba, la estación de menor variabilidad fue Sayausí TO2 $(\sigma=2.2)$ y la de mayor variabilidad fue Puente del Vado TO3 $(\sigma=4.42)$.

Las estaciones que presentan mayor variabilidad en su calidad deben prestar mayor atención en cuanto a los usos que pueden asignarse al recurso, los cuales dependerán del periodo climatológico. La calidad en todas las estaciones disminuye durante condiciones de estiaje y, en menor grado, en periodos lluviosos (invierno); esto significa que si, por ejemplo, el uso fuere para abastecimiento de agua potable, habrá mayor variación en las dosis de coagulantes, de ayudantes de floculación, de desinfectantes, etc., es decir, la potabilización se hace más difícil. Otro uso que puede verse afectado es el riego, debido a la probable presencia de huevos de parásitos; un aspecto importante a tener en consideración es la posibilidad de la presencia de sustancias tóxicas que en condiciones de bajo caudal pueden sobrepasar la capacidad de autodepuración de la corriente.

\subsection{Variación espacial de la calidad del agua}

Durante su recorrido la corriente incrementa el caudal por el aporte de afluentes que se incorporan al curso mayor, los cuales agregan contaminación por descargas de aguas residuales domésticas no tratadas y no interceptadas, y por acciones naturales como la escorrentía pluvial urbana y no urbana que arrastra nutrientes de fósforo y nitrógeno, por lo que la calidad disminuye progresivamente en todos los ríos y en todas las condiciones climatológicas (Fig. 3).

En el río Tarqui la calidad en todo su recorrido desciende hasta 20 unidades en promedio; pero los tramos de mayor descenso ocurren entre las dos primeras y entre las dos últimas estaciones; es decir la contaminación aportada por la población de la Parroquia Cumbe, y la debida a la urbanización del Cantón Cuenca en el último tramo, son significativas, tanto que en la última estación ( $A J$ Yanuncay TA7) la calidad desciende a la categoría de "contaminado" en tres monitoreos. El río recupera la calidad en cinco unidades en promedio en DJ Zhucay T5, lo que significa que el río Zhucay alivia la contaminación del Tarqui. Los resultados indican que la calidad en el río Tarqui es superior en los monitoreos de caudal medio, y el mayor descenso se presenta en estiaje.

Para el río Yanuncay la calidad a lo largo de su recorrido, desciende en promedio 16 unidades, pero el tramo de mayor deterioro, con seis puntos de diferencia, ocurre entre Los Tres Puentes Y5 y la estación UDA Y6, por la intensa urbanización y descargas de aguas residuales industriales a pequeña escala y clandestinas. Entre las estaciones San Joaquín Y3 y Avda. Loja Y4, hay un descenso de caudal en tres de los nueve monitoreos realizados; en este tramo probablemente hay extracción de agua, lo cual incide en el valor del ICA sobre todo en estiaje, como se observa en el monitoreo nueve, en donde hay un descenso de calidad de 17 puntos. La calidad del 
río es superior en caudal medio y el mayor deterioro se registra en caudal bajo.

En el río Machángara la calidad disminuye en 16 puntos en promedio durante su recorrido. Es el cuerpo superficial más protegido en su zona alta, con un ICA promedio en Chiquintad M1 de 73.9 el más alto de todos los ríos. Calidad superior se presenta en caudal medio, y desmejora levemente en caudales altos o bajos.

En el río Tomebamba, entre la estación Sayausí TO2 y Puente del VadoTO3, la calidad disminuye hasta en 13 puntos en algunos monitoreos; presumiblemente debido a la actividad agrícola y la intensa urbanización en el tramo considerado; después, la calidad continúa disminuyendo, pero con menor variación entre estaciones, hasta alcanzar condiciones de contaminado en la última estación (Río Cuenca) en casi todos los monitoreos; la calidad, en promedio, disminuye cerca de 24 puntos. En las dos últimas estaciones (antes de la PTAR TO6, y en Challuabamba TO7), ya en el río Cuenca, la calidad ya no depende del período estacional, siempre está contaminado, presentando ICAs por debajo de 50, ocurriendo la condición más crítica en estiaje, cuando el bajo caudal del río ya no puede depurar la carga contaminante y constante de agua residual no tratada ni interceptada de la urbanización existente en Challuabamba, obteniendo ICAs hasta de 41.9.

Tabla 3. Criterio general de la calidad según el valor del índice de calidad de agua (ICA); (SEMARNAT, s. f.).

\begin{tabular}{|c|c|c|c|c|c|}
\hline ICA & $\begin{array}{l}\text { Criterio } \\
\text { General } \\
\end{array}$ & Abastecimiento Público & Recreación & $\begin{array}{c}\text { Pesca y Vida } \\
\text { Acuática } \\
\end{array}$ & Industrial y Agrícola \\
\hline 100 & \multirow{2}{*}{$\begin{array}{c}\text { No } \\
\text { contaminado }\end{array}$} & No requiere purificación & \multirow{3}{*}{$\begin{array}{l}\text { Aceptable para } \\
\text { cualquier deporte } \\
\text { acuático }\end{array}$} & \multirow{3}{*}{$\begin{array}{l}\text { Aceptable para } \\
\text { todos los } \\
\text { organismos }\end{array}$} & $\begin{array}{l}\text { No requiere } \\
\text { purificación }\end{array}$ \\
\hline 90 & & Ligera purificación & & & \multirow{2}{*}{$\begin{array}{c}\text { Ligera purificación } \\
\text { para algunos procesos }\end{array}$} \\
\hline 80 & Aceptable & \multirow{3}{*}{$\begin{array}{l}\text { Mayor necesidad de } \\
\text { tratamiento }\end{array}$} & & & \\
\hline 70 & \multirow{2}{*}{$\begin{array}{c}\text { Poco } \\
\text { Contaminado }\end{array}$} & & \multirow{2}{*}{$\begin{array}{l}\text { Aceptable no } \\
\text { recomendado }\end{array}$} & $\begin{array}{c}\text { Aceptable excepto } \\
\text { especies muy } \\
\text { sensibles }\end{array}$ & \multirow{2}{*}{$\begin{array}{l}\text { Sin tratamiento para } \\
\text { industria normal }\end{array}$} \\
\hline 60 & & & & $\begin{array}{c}\text { Dudoso para } \\
\text { especies sensibles }\end{array}$ & \\
\hline 50 & \multirow{2}{*}{ Contaminado } & Dudoso & $\begin{array}{c}\text { Dudoso para } \\
\text { contacto directo }\end{array}$ & \multirow{2}{*}{$\begin{array}{l}\text { Solo organismos } \\
\text { muy resistentes }\end{array}$} & \multirow{2}{*}{$\begin{array}{l}\text { Tratamiento en la } \\
\text { mayor parte de la } \\
\text { industria }\end{array}$} \\
\hline 40 & & \multirow{3}{*}{ No Aceptable } & $\begin{array}{c}\text { Sin contacto con } \\
\text { el agua }\end{array}$ & & \\
\hline$\frac{30}{20}$ & \multirow{2}{*}{$\begin{array}{c}\text { Altamente } \\
\text { contaminado }\end{array}$} & & $\begin{array}{c}\text { Señal de } \\
\text { contaminación }\end{array}$ & \multirow{2}{*}{ No aceptable } & Uso muy restringido \\
\hline 10 & & & No aceptable & & No aceptable \\
\hline
\end{tabular}
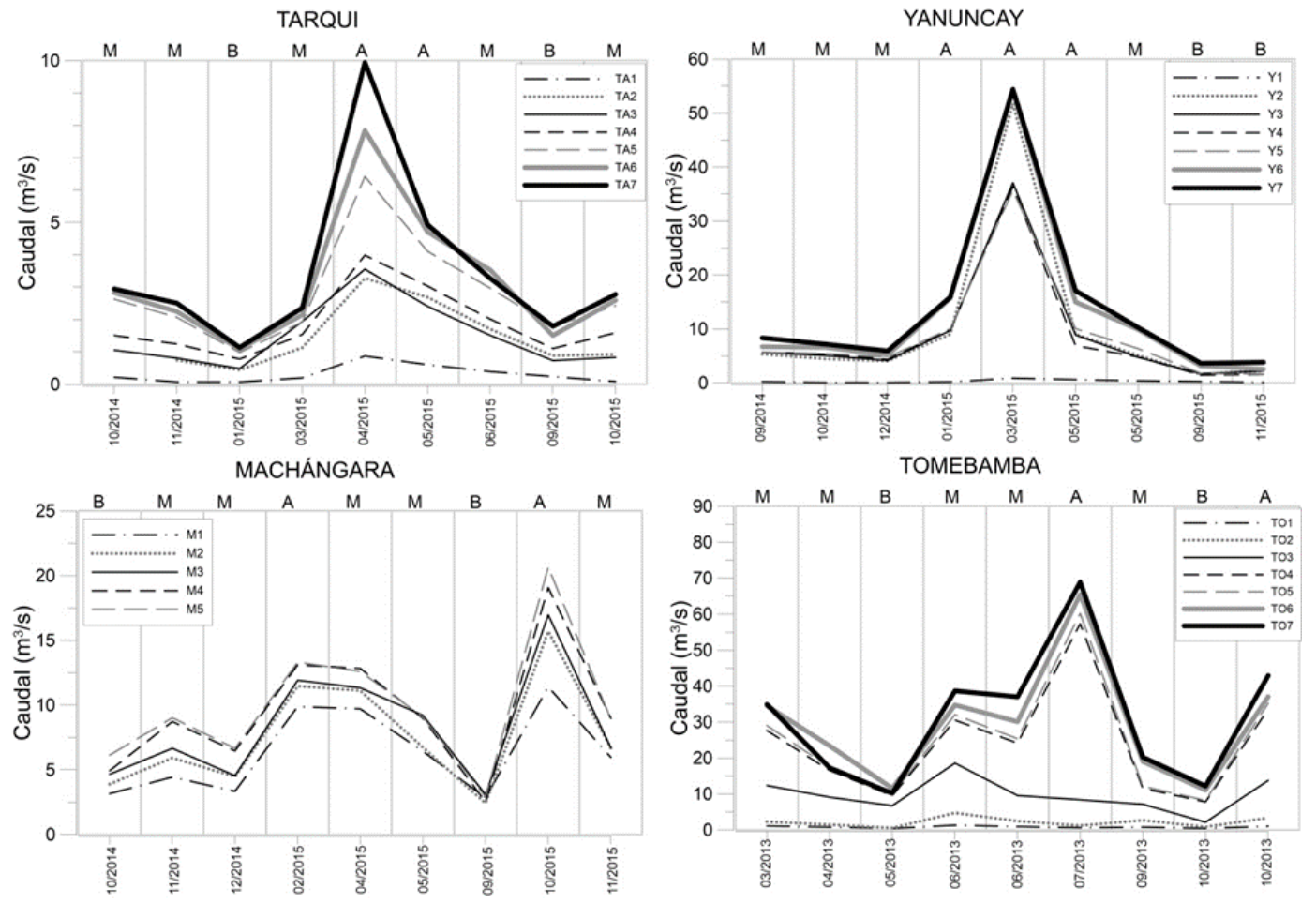

Figura 2. Evolución del caudal durante el periodo de monitoreo en los ríos evaluados (A, M y B = monitoreo en caudal alto, medio y bajo, respectivamente). 

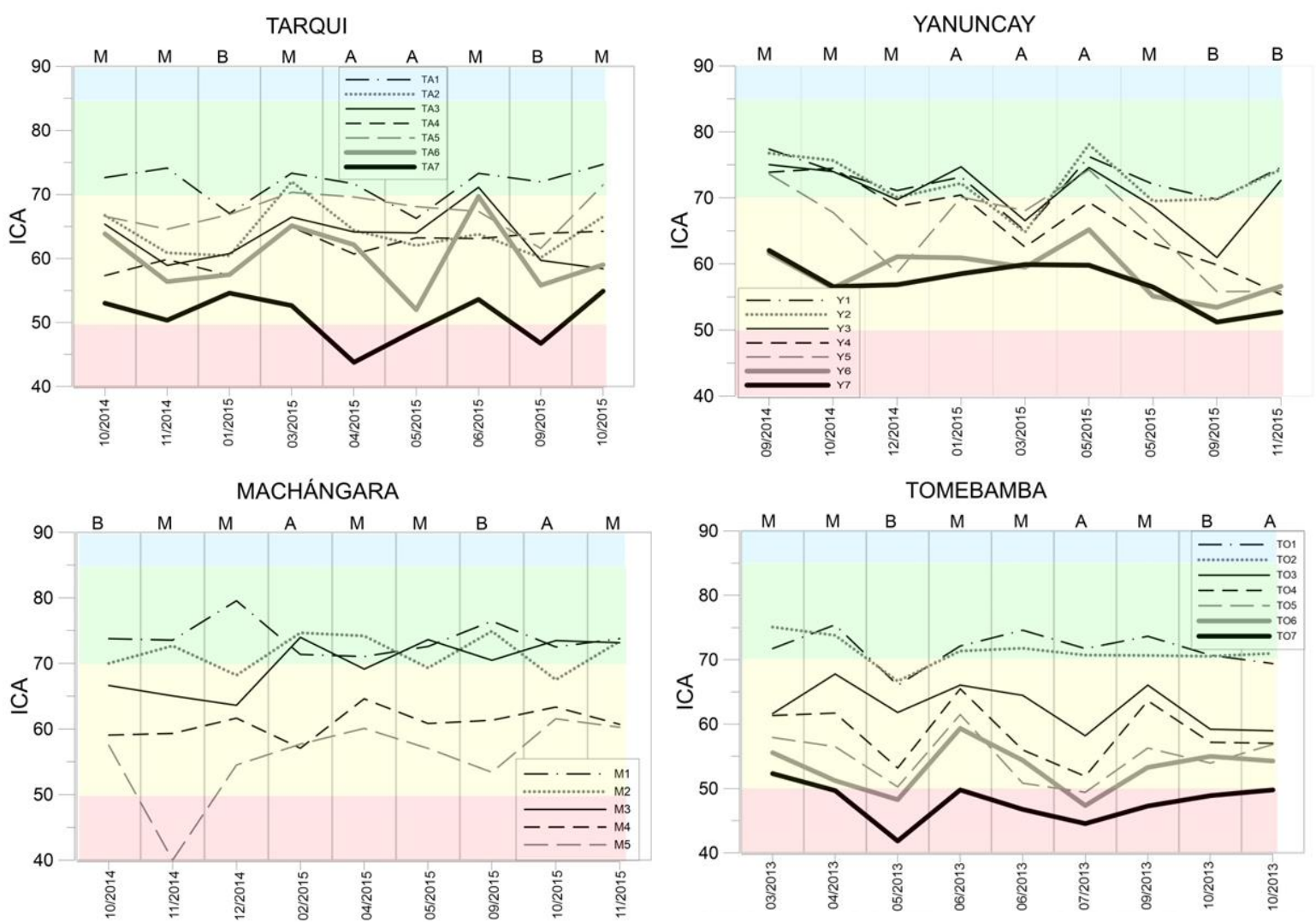

Figura 3. Valores del índice de calidad de agua en los cuatros ríos monitoreados durante el periodo evaluado ( $\mathrm{A}, \mathrm{M}$ y $\mathrm{B}=$ monitoreo en caudal alto, medio y bajo, respectivamente; zonas de color azul, verde, amarillo y rojo claros corresponden, respectivamente, a no contaminado, aceptable, poco contaminado y contaminado).
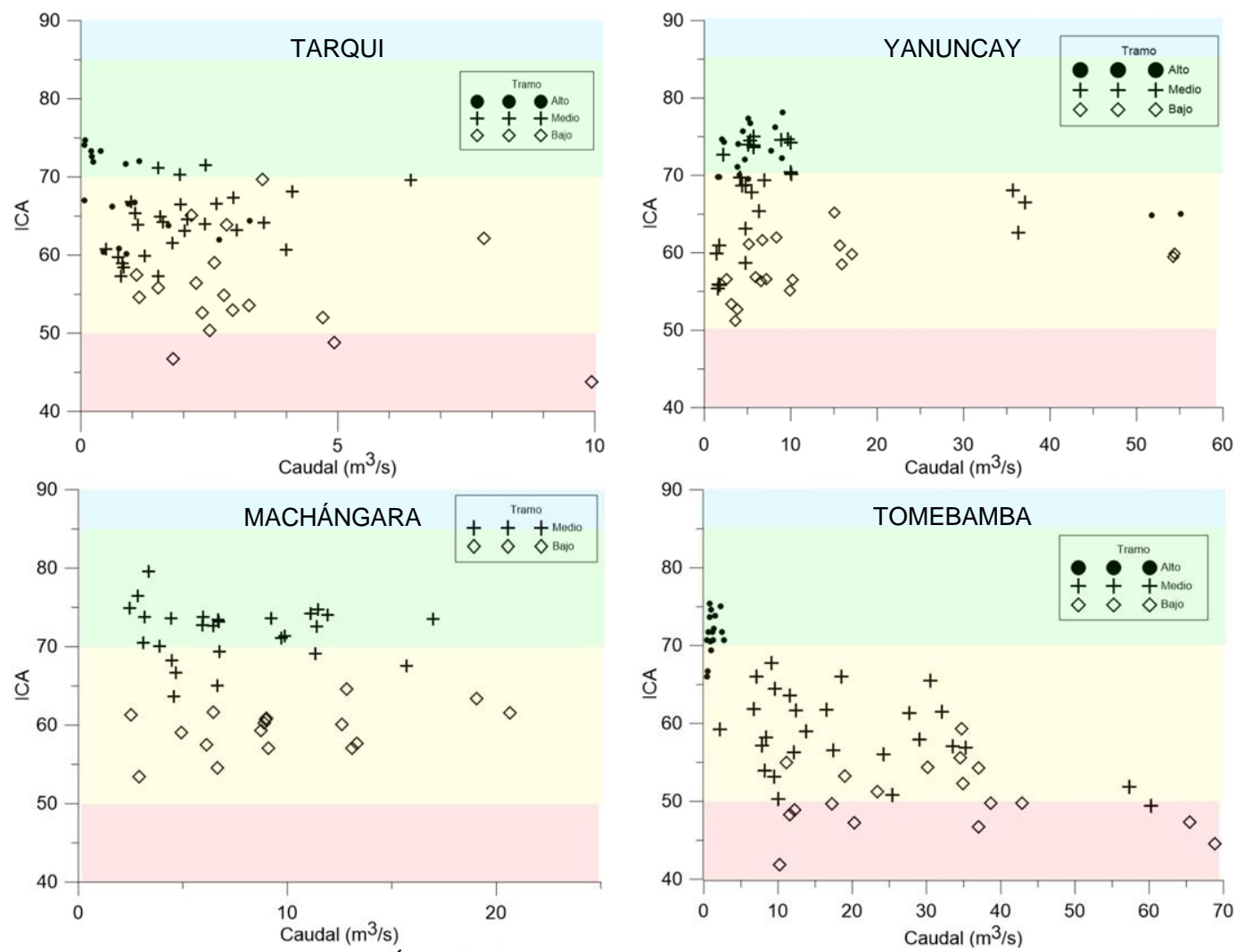

Figura 4. Influencia del caudal sobre el Índice de Calidad del Agua para los ríos evaluados. (El tipo de símbolo utilizado corresponde a la condición de caudal durante el monitoreo: alto, medio o bajo; las zonas de color azul, verde, amarillo y rojo claros corresponden, respectivamente, a no contaminado, aceptable, poco contaminado y contaminado). 


\subsection{Influencia del caudal sobre el ICA}

Para analizar la influencia del caudal sobre el ICA se ha particionado cada río de la siguiente manera: (i) tramo alto: corresponde a zonas no urbanizadas, con escasa población circundante y actividades agropecuarias escasas, (ii) tramo medio: corresponde a un área previa al ingreso al casco urbano de la ciudad de Cuenca, (iii) tramo bajo: corresponde a puntos ubicados dentro del casco urbano de la ciudad o después de él. Los resultados de este análisis se presentan para cada río en la Figura 4.

El río Tarqui puede catalogarse como "poco contaminado" en todos sus tramos y en ocasiones en caudales bajos el tramo alto presenta condiciones aceptables de calidad. Sin embargo, no se evidencia una incidencia significativa del caudal sobre la calidad de este río. Se observa también que el ICA en la Tramo Alto y Medio varía dentro de un rango entre 55 y 75 durante todo el periodo de estudio, no así en la parte baja se evidencian valores muy dispersos en un rango desde 42 hasta 70 . En el río Yanuncay, en el tramo alto, se observa que en caudales por debajo de $\operatorname{los} 10 \mathrm{~m}^{3} \mathrm{~s}^{-1}$ se mantiene una calidad aceptable, obteniendo valores de ICA cercanos a 80. Sin embargo, en un monitoreo con un caudal 5 veces mayor al medio, su calidad disminuye apenas en 5 puntos aproximadamente, debido a la erosión y la contaminación difusa. Los tramos medios y bajos se mantienen siempre en un estado Poco Contaminado. Es evidente en el tramo medio y bajo, que a medida que incrementa el caudal, el efecto de dilución se hace significativo y su calidad tiende a mejorar. Para el río Machángara se optó por dividirlo únicamente en tramo medio y bajo ya que desde la primera estación existen varias poblaciones establecidas. No fue posible acceder a los tramos altos por movilización y la restricción de ingreso a estas zonas ya que es una cuenca protegida. Sin embargo, es evidente que el caudal no incide en el tramo medio puesto que, con respecto a la mejor condición, para la que se obtuvo un ICA de aproximadamente 80 a un caudal de $3 \mathrm{~m}^{3} / \mathrm{s}$, si se quintuplica este caudal el ICA apenas disminuye en 6 unidades manteniéndose como Aceptable. Con respecto al tramo bajo, la calidad se mantiene estable con excepción de un monitoreo en donde se registró toxicidad en el río, que puede ser debido a descarga de tipo industrial o a un mal funcionamiento puntual de los interceptores marginales. Por otra parte, en el río Tomebamba se distinguen claramente tres grupos de ICA. En el tramo alto la calidad es Aceptable para rangos menores de caudal de $5 \mathrm{~m}^{3} / \mathrm{s}$. En el tramo medio la calidad se mantiene como poco contaminado en un rango de caudales hasta los 60 $\mathrm{m}^{3} / \mathrm{s}$. El tramo bajo el río Tomebamba recibe los tres afluentes, Tarqui, Yanuncay y Machángara. De manera adicional, el último punto de monitoreo se encuentra en una zona que todavía no dispone de interceptores marginales y sus aguas residuales son descargadas sin tratamiento. Se puede evidenciar en este último tramo que la calidad es baja en caudales bajos o altos, y mejora ligeramente en caudales medios. En conclusión, en todos los ríos la calidad disminuye a medida que aumenta el caudal; pero el descenso es mayor en caudales bajos, por lo que la calidad es crítica en estiaje.

\subsection{Usos del agua en los ríos de estudio}

Los valores de ICA obtenidos permiten definir los usos del agua en cada río y en cada estación (Tabla 3), siendo importante identificar aquellos que pueden asignarse en períodos de estiaje, ya que constituye la condición más crítica para la calidad.

Los ríos de mayor atención en cuanto a la contaminación y por tanto a los usos, son el Tarqui y el Tomebamba en sus zonas bajas; así, para el abastecimiento público ya es dudoso, en ambos ríos; el uso recreativo toma condiciones de aceptable no recomendable en todo el río Tarqui, y en el Tomebamba ya alcanza la condición de dudoso para contacto directo; para mantenimiento de pesca y vida acuática es decir para conservar las características del ecosistema, en el río Tarqui ninguna estación es aceptable para todos los organismos; y el Tomebamba en cambio ya alcanza condiciones de sólo organismos muy resistentes; finalmente para el uso industrial y agrícola, el río Tarqui está catalogado sin tratamiento para la industria normal en todas las estaciones, y el Tomebamba ya adquiere la condición de tratamiento en la mayor parte de la industria.

\section{DISCUSIÓN}

\subsection{Características estéticas}

En términos generales, durante el período de monitoreo, en el río Tarqui predomina el color, con altos valores de turbiedad; en el río Yanuncay predomina el color acompañado de baja turbiedad; en el río Machángara la turbiedad y el color son relativamente bajos, mientras que en el Tomebamba predomina la turbiedad. Estas variaciones afectan los usos posteriores del agua; así, la potabilización se dificulta en período invernal, mientras que en estiaje se puede incrementar la concentración de sustancias tóxicas no identificadas porque la corriente pierde capacidad de autodepuración.

En el río Machángara la regulación del caudal tiene un efecto positivo en la calidad pues presenta menos variaciones que las observadas en los otros ríos; no hay color ni turbidez significativa en invierno, y en verano tampoco hay concentración de solución. Los sólidos suspendidos, que tienen una relación directa con la turbiedad, presentan los niveles más altos en los ríos Tarqui, Yanuncay y Tomebamba y en condiciones de lluvia; pero es necesario considerar el aporte de sólidos por escorrentía pluvial urbana y por erosión en las subcuencas altas, por lo que es necesaria la protección de los suelos para evitar su deterioro, y en estudios posteriores establecer la diferenciación entre las dos fuentes de generación de sólidos.

Durante los días anteriores a un evento de lluvia se produce un proceso de acumulación de carga contaminante en superficie; esta acumulación se debe a diferentes fuentes de contaminación, entre las cuales cabe destacar: residuos vegetales y restos de animales domésticos; compuestos y sustancias en suspensión que han precipitado, residuos tóxicos procedentes de emisiones de vehículos, etc. Durante un evento de lluvia extremo, el agua arrastra todos estos elementos transportando la carga contaminante hacia la red y evacuándola hacia el medio receptor (TempranoGonzález, Gabriel-Cervigni, Suárez-López, \& TejeroMonzón, 1996). 
Tabla 4. Valores máximos (y mínimos entre paréntesis) de características físicas, químicas y biológicas de los ríos estudiados.

\begin{tabular}{cccccc}
\hline \multirow{2}{*}{ Parámetro } & \multicolumn{4}{c}{ Río } \\
\cline { 2 - 5 } & & Tarqui & Yanuncay & Machángara & Tomebamba \\
\hline Color & UC (Pt-Co) & $152(23)$ & $244(7)$ & $61(2)$ & $59(12)$ \\
\hline Turbiedad & NTU (FTU) & $70.4(3.8)$ & $163(0.8)$ & $54.7(2.26)$ & $104(0.91)$ \\
\hline Sólidos Susp. & $\mathrm{mg} \mathrm{L}^{-1}$ & $177(1)$ & $631(1)$ & $134(2)$ & $186(40)$ \\
\hline Oxígeno Disuelto & $\mathrm{mg} \mathrm{L}^{-1}$ & $8.46(4.6)$ & $8.7(5.35)$ & $8.9(6.25)$ & $8.53(4.41)$ \\
\hline DBO5 & $\mathrm{mg} \mathrm{L}^{-1}$ & $11.6(.02)$ & $14.02(.07)$ & $10.08(.15)$ & $10.12(.01)$ \\
\hline Conductividad & $\mathrm{uS} \mathrm{cm}^{-1}$ & $336(37.3)$ & $213(25.2)$ & $150.3(67.2)$ & $240(87.3)$ \\
\hline Cloruros & $\mathrm{mg} \mathrm{L}^{-1}$ & $71(4.1)$ & $27.5(4.1)$ & $9.1(3)$ & $19(2)$ \\
\hline E. Coli & $\mathrm{NMP} / 100 \mathrm{ml}$ & $7.00 \mathrm{E}+07(2.00 \mathrm{E}+03)$ & $1.70 \mathrm{E}+07(45)$ & $2.00 \mathrm{E}+06(33)$ & $1.10 \mathrm{E}+07(13)$ \\
\hline
\end{tabular}

\subsection{Nutrientes}

\section{Nitrógeno amoniacal}

En el río Tarqui la concentración aumentó en estiaje (1.67 $\mathrm{mg} \mathrm{L}^{-1}$ ), mientras que en periodo de lluvias se produjo arrastre. En el Yanuncay la mayor concentración también sucedió en estiaje ( $\left.1.06 \mathrm{mg} \mathrm{L}^{-1}\right)$ pero no se nota arrastre en invierno; el Machángara presentó niveles bajos en la parte alta, y en estiaje no aumentó la concentración, debido a que su caudal está regulado; el valor máximo se observó en la última estación $\left(0.99 \mathrm{mg} \mathrm{L}^{-1}\right)$. En el río Tomebamba, en la zona alta se presentaron los valores más bajos de entre todos los ríos $\left(0.01 \mathrm{mg} \mathrm{L}^{-1}\right)$, pero en la parte baja (Challuabamba) se observaron los más altos, aumentaron en lluvia y en estiaje (3.1 $\left.\mathrm{mg} \mathrm{L}^{-1}\right)$.

La concentración de nitrógeno amoniacal es importante por su relación con el $\mathrm{pH}$; un incremento de 7.4 a 8.0 reduce a la mitad el nivel de la concentración tóxica de este compuesto $\left(\mathrm{NH}_{3}\right)$; el amoníaco ionizado $\left(\mathrm{NH}^{+}\right)$que predomina a bajos niveles de $\mathrm{pH}$ es menos tóxico que las formas no ionizadas $\left(\mathrm{NH}_{3}\right)$; algunas estaciones alcanzan un pH igual o mayor a 8 (Tebbutt, 1998b).

\section{Nitrógeno de Nitratos}

Cuando la materia orgánica se descompone en condiciones aerobias, la primera forma de nitrógeno en aparecer es el amoníaco, procedente de las proteínas, urea y aminoácidos, el cual paulatinamente se va oxidando hasta su forma final que son los nitratos; pero esta nitrificación requiere tiempo porque es una reacción cinética. Durante el periodo de lluvias, los ríos Tarqui, Machángara y Tomebamba presentaron una concentración máxima de $2.14,2.52$ y $0.52 \mathrm{mg} \mathrm{L}^{-1}$, respectivamente; solo el Yanuncay presentó una concentración máxima de $2.69 \mathrm{mg} \mathrm{L}^{-1}$ durante el periodo de estiaje. Los resultados de las formas de nitrógeno muestran que en el río Tomebamba la concentración de amoníaco es mucho mayor que en los otros ríos, y la de nitratos, en cambio, es la más baja; lo que indica que la contaminación en este río es reciente, es decir hay un aporte permanente de materia orgánica por aguas residuales domésticas, a la cual le hace falta tiempo para descomponerse, representando condiciones críticas de contaminación, que no se observaron en los otros ríos.

\section{Fósforo total}

En el río Tarqui la concentración máxima fue de $3.16 \mathrm{mg}$ $\mathrm{L}^{-1}$ en invierno, y mínima de $0.46 \mathrm{mg} \mathrm{L}^{-1}$ en estiaje; esto significa que en periodos de lluvia hay arrastre de fósforo debido a la poca vegetación de soporte en la subcuenca, además, hay más actividad ganadera y agrícola que en los otros ríos; el $90 \%$ del fósforo es orgánico, lo que indica que procede de abonos, plaguicidas, detergentes sintéticos, etc. En el Yanuncay, la concentración máxima ocurrió durante el periodo de estiaje $\left(0.461 \mathrm{mg} \mathrm{L}^{-1}\right)$ y no se incrementó en invierno; además, un $25 \%$ del fósforo fue de origen orgánico. En el Machángara, la concentración máxima fue de $0.358 \mathrm{mg} \mathrm{L}^{-1}$ en invierno (periodo lluvioso), lo cual significa poco arrastre de nutrientes, además de actividades agrícolas y ganaderas a pequeña escala y controladas. En el Tomebamba, las concentraciones altas variaron entre 4 y $7 \mathrm{mg} \mathrm{L}^{-1}$ en casi todos los monitoreos, independientemente del período climático, predomina el fósforo orgánico, lo que significa un uso intensivo de los abonos fosforados en esta subcuenca, descargas de detergentes sintéticos y principalmente de excretas humanas. En síntesis, el río Tarqui aporta mayor cantidad de nutrientes de nitrógeno y fósforo, por arrastre de sedimentos debido a la erosión superficial; datos coincidentes con los obtenidos en los Planes Maestros de Agua Potable y Alcantarillado de ETAPA EP del año1987.

\subsection{Oxígeno disuelto y Demanda Bioquímica de Oxígeno $\mathrm{DBO}(5)$}

Los valores máximos y mínimos para los ríos evaluados se muestran en la Tabla 4. Los valores máximos de oxígeno fueron registrados en las primeras estaciones y sobre todo en época de lluvias, debido a un incremento en la velocidad y por tanto a la capacidad de reaeración. En todos los ríos los niveles de oxígeno fueron superiores a los de saturación, a la temperatura correspondiente, esto indica que se favorecen los procesos aerobios de descomposición, esto es típico en ríos de alta montaña; en estiaje, en cambio, el OD desciende hasta $4.6 \mathrm{mg} \mathrm{L}^{-1}$, presentándose un déficit que representa un riesgo para especies biológicas sensibles, sin comprometer la vida acuática superior. Esta afección se observa sobre todo en las últimas estaciones del río Tomebamba (río Cuenca); en términos generales, el río Machángara presenta la menor variación de oxígeno mientras que el Tomebamba la más importante. La concentración de oxígeno disuelto tiene un especial efecto en la toxicidad de los metales pesados; si la concentración disminuye a la mitad del valor de saturación, los niveles de toxicidad de estos metales disminuyen al 70\%, confirmando la condición crítica de la contaminación en estiaje (Tebbutt, 1998b). 
En cuanto a la $\mathrm{DBO}_{(5)}$, esta alcanza valores máximos, por encima de $10 \mathrm{mg} \mathrm{L}^{-1}$, para todos los ríos evaluados y durante el período de estiaje; en cambio, en tiempo lluvioso, las concentraciones son menores, compatibles con el efecto de dilución y lavado de la biomasa.

\subsection{Conductividad, cloruros y Escherichia coli}

Los valores mínimos de conductividad y cloruros se registraron en las primeras estaciones, y los máximos al final del recorrido; la menor variación de estos dos parámetros ocurrió en el Machángara, y la más significativa en el Tarqui, aunque en este río es importante la conductividad de origen geológico. El parámetro que más incide en la calidad es el alto contenido de bacterias coliformes fecales en todos los ríos (Tabla 4)

La empresa ETAPA EP, en base a un estudio de la calidad de aguas en las zonas bajas de los cuatro ríos de la ciudad, en el año 2012, mediante el uso del índice tradicional WQI de 9 parámetros (desarrollado por la Fundación Nacional de Saneamiento) concluyó que los parámetros que más afectan al mantenimiento del ecosistema son la $\mathrm{DBO}_{5}$ y el contenido de Oxígeno Disuelto. El aporte del presente trabajo es el estudio de la calidad con un modelo que incluye parámetros químicos que permiten identificar el origen de la contaminación (orgánico o inorgánico) a través de medidas como la conductividad, cloruros, alcalinidad, y dureza total; el presente índice, basado en 18 parámetros, también aporta información sobre el momento en que se produce la contaminación, a través de la evolución de las formas de nitrógeno; finalmente, la medición de los caudales es otro parámetro útil para una evaluación más integral de la calidad de agua (ETAPA, 2008).

En el presente estudio el río Tomebamba, en la zona baja (río Cuenca), registró índices de Coliformes semejantes a los reportados por ETAPA EP en el año 2012. Se espera que los actuales niveles de contaminación sean menores ya que, según información suministrada por ETAPA, en el año 2014 se construyó el interceptor en la margen derecha del río Cuenca, en una longitud de $4.2 \mathrm{~km}$; y entre el 2014 y el 2015, el interceptor en la margen izquierda del mismo río, en una longitud de $8.9 \mathrm{~km}$.

El modelo de calidad utilizado en el presente estudio es válido para un diagnóstico preliminar de los cuerpos receptores, especialmente cuando se trata de estimar la calidad en el estado preoperacional, o línea base, aspecto indispensable para evaluar el posible impacto ambiental que obras de diferente naturaleza puedan producir sobre la calidad del cuerpo receptor.

\subsection{Metas de calidad propuestas}

En los Estudios de Diagnóstico y Factibilidad de los "Planes Maestros de Agua Potable y Alcantarillado del Área Metropolitana de la ciudad de Cuenca" en 1987, se fijó una meta de calidad, a fin de que el agua de los ríos sea apta para algunos usos como: estético, recreativo por contacto primario y secundario, y para riego. La aptitud del agua para estos usos requiere, entre otros, un valor de bacterias coliformes fecales (Escherichia coli), hasta de $1000 \mathrm{NMP} / 100 \mathrm{ml}$, valor recomendado por la Agencia de Protección Ambiental de los EEUU (EPA). En este aspecto, la Normativa Ecuatoriana TULSMA considera los usos del agua, con sus correspondientes criterios para coliformes totales y fecales (Tabla 5). Por lo visto, el criterio de meta tiene total relación con los exigidos por la Normativa Ecuatoriana, excepto para contacto primario, (200 NMP/100 ml).

Tabla 5. Criterios de calidad microbiológicos, según la normativa ecuatoriana.

\begin{tabular}{lll}
\hline \multicolumn{1}{c}{ Uso } & \multicolumn{1}{c}{$\begin{array}{c}\text { Coliformes } \\
\text { Totales } \\
\text { NMP/100 ml }\end{array}$} & $\begin{array}{c}\text { Coliformes } \\
\text { Fecales } \\
\text { NMP/100 ml }\end{array}$ \\
\hline $\begin{array}{l}\text { Fuentes de agua } \\
\text { para consumo } \\
\text { humano y } \\
\text { doméstico }\end{array}$ & 1000 & No reporta valor \\
$\begin{array}{l}\text { Preservación de } \\
\text { vida acuática y } \\
\text { silvestre }\end{array}$ & No reporta valor & No reporta valor \\
$\begin{array}{l}\text { Uso agrícola } \\
\text { Agua para riego }\end{array}$ & No reporta valor & No reporta valor \\
$\begin{array}{l}\text { Fines recreativos, } \\
\text { por contacto } \\
\text { primario }\end{array}$ & 2000 & 200 \\
$\begin{array}{l}\text { Fines recreativos, } \\
\text { por contacto } \\
\text { secundario }\end{array}$ & 4000 & \\
\hline
\end{tabular}

Para alcanzar este nivel, es necesario disminuir la contaminación bacteriana en 2, 3 y hasta 4 ciclos logarítmicos en los ríos de Cuenca, pero sobre todo en el río Tomebamba en su parte baja (río Cuenca), el cual, desde la estación Puente del Vado requiere atención, en todas las condiciones climatológicas. Este nivel de reducción no es fácil de alcanzar si se considera el aporte de la contaminación difusa por fuentes no puntuales, que son difíciles o imposibles de controlar, como: descargas de escurrimiento directo superficial de las áreas urbanas, la carga de sedimentos por erosión del suelo en las subcuencas, la contaminación por escorrentía pluvial no urbana, la descarga y rebose de los colectores marginales hacia los cuerpos superficiales y sobre todo los derrames sin control de agua de lluvia en los alcantarillados combinados que se incluyen también en la categoría de contaminación no puntual.

Cuando se practica un control eficiente de las fuentes puntuales, por ejemplo, a través de los interceptores marginales, las fuentes no puntuales pueden tener una contribución significativa en la contaminación; siendo importante que, al preparar las políticas de control de la contaminación, se tenga en cuenta esta contribución ya que de otra manera se pueden sobreestimar las metas de la política para el control del medio ambiente (Tebbutt, 1998b).

Al tratar de resolver el problema de la contaminación de los ríos, no se pueden centrar todos los esfuerzos en la construcción de depuradoras y en el tratamiento de las aguas residuales pues aproximadamente un 50\% de la contaminación vertida al medio receptor proviene de los vertidos en tiempo de lluvia. En muchas ocasiones, los logros conseguidos mediante la construcción de depuradoras y el tratamiento de las aguas en tiempo seco quedan anulados por este tipo de descargas (TempranoGonzález et al., 1996). 


\subsection{Plan de vigilancia de la calidad de los ríos}

Un monitoreo trimestral, incluyendo tiempos de paso y mediciones de caudal, permitirá un diagnóstico oportuno de la calidad, sobre todo en las zonas bajas y en estiaje, que representan las condiciones más desfavorables. Un plan de vigilancia de este tipo permitirá evaluar la eficiencia de los interceptores marginales. Según información proporcionada por ETAPA EP, en el período 2014-2018 se han construido en total $34.8 \mathrm{~km}$ de interceptores, y entre el 2018 y el 2019 se construyeron los interceptores de la Quebrada Alpayacu $(0.4 \mathrm{~km})$ y del río Machángara $(5.6 \mathrm{~km})$. Los nuevos interceptores se van sumando a la red ya existente en los diferentes ríos y quebradas del sector. El plan de vigilancia permitirá detectar condiciones de riesgo toxicológico sobre todo cuando el agua es destinada para consumo humano, debido a descargas accidentales y/o clandestinas de materiales tóxicos $\mathrm{y}$, aunque su identificación y cuantificación no son sencillas, sí es posible implementar "bioensayos de control" que adviertan la presencia de material peligroso.

\section{CONCLUSIONES}

En todos los ríos el índice de E. Coli es el parámetro que más incide en la calidad. El análisis estadístico muestra que en condiciones de estiaje este parámetro aporta con menos de una unidad de calidad al valor del ICA total, sobre todo en las zonas medias y bajas. Es de esperar que la construcción de los interceptores marginales (onerosa obra de saneamiento) tenga un efecto positivo en la reducción de la contaminación microbiana, sin aspirar a los niveles deseados (NMP/100 ML, semejantes a 1,000) por los factores anteriormente expuestos. Menos significativos que la polución microbiana, son la contaminación por materia orgánica y el descenso de oxígeno. Otros parámetros que restan calidad al recurso son los nutrientes de nitrógeno y fósforo, provenientes de fuentes puntuales como descargas de aguas residuales domésticas y fuentes no puntuales, difíciles e imposibles de controlar como lo son las descargas de escurrimiento directo superficial procedentes de áreas urbanas y rurales.

De los ríos estudiados, el Tomebamba puede ser catalogado como el cuerpo receptor más crítico en lo que se refiere a contaminación. En su parte baja (río Cuenca), su único uso posible corresponde a "transporte $\mathrm{y}$ asimilación de desechos". En general, en las cabeceras de los ríos, la calidad bacteriológica es satisfactoria, pero esta calidad comienza a deteriorarse paulatinamente a partir de la parte media, experimentando una notable degradación en el área urbana de la ciudad, esto no solo ocurre con la calidad bacteriológica sino de todas las características evaluadas. Los recuentos de coliformes son superiores con tres o cuatro ciclos logarítmicos, a los establecidos por los criterios de calidad para varios usos, por esto, la contaminación bacteriana constituye el mayor problema en la calidad de los cuerpos receptores, representando así un problema de salud pública. El río Machángara presentó la calidad más alta durante el período de evaluación, con un ICA máximo de 79.6 y un mínimo de 53.4; no obstante, en un monitoreo se detectó toxicidad en la última estación, esto es, pasando la zona del parque industrial, aunque esta situación fue esporádica, es importante un control sobre el vertido de las descargas industriales sobre todo de las instantáneas, las cuales según su naturaleza inciden fuertemente en el ecosistema.

Los cuatro ríos evaluados pertenecen a subcuencas frágiles, de alta pendiente, con períodos de retención cortos. La naturaleza química del agua demuestra poca capacidad de amortiguamiento, con alcalinidades que no superan los $65 \mathrm{mg} / \mathrm{l}$ como $\mathrm{CaCO}_{3}$, en condiciones naturales; en general son aguas blandas, con bajas concentraciones de calcio y magnesio; bajas concentraciones de elementos como el sodio o potasio, lo que incrementa el efecto tóxico de metales pesados como el plomo y el cinc para los peces, por la débil posibilidad del agua para complejar los metales pesados en estas condiciones; se trata entonces de equilibrios químicos lábiles y de fácil modificación.

Previo a la asignación o concesión del recurso agua, organismos de control como la SENAGUA deben tomar en consideración estas características fundamentales que demuestran la fragilidad de los sistemas evaluados. Cualquier alteración de las zonas altas de estos ríos -por ejemplo, concesiones para actividades mineras- podría repercutir de forma directa y rápida en la calidad del agua, aspecto crítico cuando su uso es para consumo humano.

\section{RECOMENDACIONES}

Es necesaria una adecuada planificación urbana, que garantice la conexión total de las redes de alcantarillado a los interceptores marginales para impedir el vertido directo del agua residual doméstica a los cuerpos receptores. En cuanto al control de la calidad del agua, se debería iniciar un estudio relacionado con la formulación de un Índice de Calidad que incluya la presencia de sustancias tóxicas para ríos de alta montaña; para ello es necesario seleccionar el o los indicadores de toxicidad que sean representativos de las aguas estudiadas; por el alto contenido de nutrientes de fósforo en el río Tomebamba, quizás los plaguicidas órganos fosforados puedan considerarse los adecuados; en el río Yanuncay, el pronunciado color, acompañado de baja turbiedad, merece el estudio de su naturaleza; es decir, la identificación de las sustancias húmicas presentes, las cuales, de no ser eliminadas eficientemente en los procesos de potabilización convencionales, durante la cloración pueden generar subproductos como los trihalometanos (THM), de reconocido efecto tóxico; estudios realizados sobre estas sustancias se han enfocado en la búsqueda de Cloroformo $\mathrm{CHCl}_{3}$; Bromo diclorometano $\mathrm{CHBrCl}_{2}$; Dibromoclorometano $\mathrm{CHBr}_{2} \mathrm{Cl}$ Tribromometano $\mathrm{CHBr}_{3}$, o de sus principales precursores como los ácidos húmicos y los ácidos fúlvicos. En el río Machángara, después del Parque Industrial, los elementos tóxicos de interés pueden ser los metales pesados, como plomo, mercurio, arsénico o aluminio. Todas las sustancias mencionadas están 
citadas en la Normativa TULSMA, para los distintos usos del agua. La razón de su búsqueda es importante por el efecto tóxico sobre el hombre y los ecosistemas en general; la severidad de sus efectos depende de la dosis recibida, el período de exposición y otros factores ambientales. La principal preocupación en el abastecimiento del agua potable es el efecto a largo plazo de la exposición crónica a niveles bajos de compuestos tóxicos, los cuales no son eliminados por los tratamientos convencionales aplicados en nuestro medio, por lo que la alternativa más segura es la protección del agua, desde su fuente (Pauta-Calle, 2014).

Todos los suministros de agua potable deben implementar un sistema de control de calidad del agua distribuida, no obstante, este control es variable en el tiempo y en espacio; para suministros pequeños, y sobre todo a nivel rural, esta actividad consistirá en la detección de organismos indicadores de contaminación fecal, para eliminar el riesgo de la transmisión de enfermedades hídricas, las cuales si no son oportunamente atendidas pueden producir la muerte de los consumidores en menos de una semana. Para suministros grandes y con potencial técnico y económico, el control de la calidad está encaminado a la búsqueda de sustancias peligrosas que, ingeridas en pequeñas dosis y por largos períodos, pueden producir una toxicidad crónica; por lo que se sugiere a los organismos de control, la selección, para cada una de las subcuencas, de indicadores de toxicidad del agua en los ríos, en función de los usos del suelo.

\section{REFERENCIAS}

American Public Health Association (2005). Eaton, A. D., Clesceri, L. S., Rice, E. W., Greenberg, A. E., \& Franson, M. A. H. (Eds.). Standard Methods for the Examination of Water \& Wastewater, Centennial Edition (21 edition).

Carretero, M. I., \& Pozo-Rodriguez, M. (2007). Mineralogía aplicada. Salud y medio ambiente. Recuperado de https://www.paraninfo.es/catalogo/9788497324878/ mineralogia-aplicada--salud-y-medio-ambiente

Catalán-La Fuente, J., \& Catalán-Alonso, J.-M. (1992). Ríos: Caracterización y calidad de sus aguas.

Chang-Gómez, J.-V. (2009). Índices de calidad del agua-ICA. Recuperado de http://www.dspace.espol.edu.ec/handle/123456789/6 147

Cude, C. G. (2001). Oregon Water Quality Index a tool for evaluating water quality management effectiveness. JAWRA Journal of the American Water Resources Association, 37(1), 125-137. https://doi.org/10.1111/j.1752-1688.2001.tb05480.x

DEQ State Office. (s. f.). Water Quality-Idaho Department of Environmental Quality. Recuperado 8 de diciembre de 2019, de https://www.deq.idaho.gov/water-quality/

Dinius, S. H. (1987). Design of an Index of Water Quality. JAWRA Journal of the American Water Resources Association, 23(5), 833-843. https://doi.org/10.1111/j.1752-1688.1987.tb02959.x

Washington, DC: Amer Public Health Assn.
ETAPA. (2008). Evolución de la calidad del agua de los tramos bajos de los ríos de la ciudad de Cuenca 2008. Dirección de Gestión Ambiental.

INEC. (2010). Población y Demografía. Recuperado 8 de diciembre de 2019, de https://www.ecuadorencifras.gob.ec/censo-depoblacion-y-vivienda/

Jones, I. (2013). The impact of extreme events on freshwater ecosystems. London, U.K.: British Ecological Society.

León-Vizcaíno, L. (1992). Indices de calidad del agua (ICA), forma de estimarlos y aplicación en la cuenca Lerma-Chapala. Presentado en VIII National Congress, 1992, Instituto Mexicano de Tecnología del Agua, Morelos. Recuperado de https://www.semanticscholar.org/paper/Indices-decalidad-del-agua-(ICA)\%2C-forma-de-y-en-laVizca\%C3\%ADno/e3ba9d2bf8f04d8662cb1e3ef5d3 81 bbfdbaef 91

Marín-Galvín, R. (2019). Fisicoquímica y microbiología de los medios acuáticos: Tratamiento y control de calidad de aguas - Dialnet (2. ${ }^{\mathrm{a}}$ ed.). Recuperado de https://dialnet.unirioja.es/servlet/libro?codigo $=13055$ 7

Metcalf \& Eddy, Inc. (2003). Wastewater Engineering: Treatment and Reuse (4. ${ }^{\mathrm{a}}$ ed.). Recuperado de https://www.iberlibro.com/servlet/BookDetailsPL?bi $=30432970902 \&$ searchurl $=$ an $\% 3$ Dmetcalf $\% 2 B e d d y$ $\% 26$ sortby\%3D20\%26tn\%3Dwastewater\%2Bengine ering\%2Btreatment $\% 2$ Breuse $\& \mathrm{~cm} \_s p=$ snippet-_srp1-_-title1

Ministerio del Ambiente. (2015). Reforma texto unificado legislación secundaria, medio ambiente (TULSMA), libro VI, Decreto Ejecutivo 3516, Registro Oficial Suplemento 2, 31/03/2003. Recuperado de http://www.ambiente.gob.ec/wpcontent/uploads/downloads/2018/05/Acuerdo097.pdf

Pauta-Calle, G. (2014). Estudio integral de la calidad del agua del río Burgay y evaluación del riesgo toxicológico por la probable presencia de plaguicidas (Master thesis, Universidad de Cuenca). Recuperado de http://dspace.ucuenca.edu.ec/handle/123456789/1983 1

Rauch, W., Henze, M., Koncsos, L., Reichert, P., Shanahan, P., Somlyódy, L., \& Vanrolleghem, P. (1998, junio 21). River water quality modelling: I. State of the art. 8. Recuperado de https://pdfs.semanticscholar.org/9a78/ea7669011a2ef b418f80016c00b2e59b712a.pdf

SEMARNAT. (s. f.). Indicadores de calidad del agua Recuperado 8 de diciembre de 2019, de http://dgeiawf.semarnat.gob.mx:8080/ibi_apps/WFSe rvlet?IBIF_ex=D3_R_AGUA05_01\&IBIC_user=dge ia_mce\&IBIC_pass $=$ dgeia_mce

Sierra-Ramírez, C. (2011). Calidad del agua. Evaluación y diagnóstico (1st ed.). Medellín, Colombia: Universidad de Medellín.

Tebbutt, T. H. Y. (1998a). 2 - Characteristics of waters and wastewaters. En T. H. Y. Tebbutt (Ed.), Principles of Water Quality control (Fifth Edition) (pp. 12-27). https://doi.org/10.1016/B978075063658-2/50003-3

Tebbutt, T. H. Y. (1998b). 9-Introduction to treatment processes. En T. H. Y. Tebbutt (Ed.), Principles of 
Water Quality control (Fifth Edition) (pp. 119-126). https://doi.org/10.1016/B978-075063658-2/50010-0

Te-Chow, V., Madiment, D., \& Mays, L. (1994).

Hidrología Aplicada (1era Ed.).

Temprano-González, J., Gabriel-Cervigni, M., SuárezLópez, J., \& Tejero-Monzón, J. (1996).

Contaminación en redes de alcantarillado urbano en tiempo de lluvia: Control en origen. Revista de Obras Públicas, 143(3352), 45-57.

Torres, P., Cruz, C., Patiño, P., Escobar, J., \& Pérez, A. (2010). Applying water quality indexes (WQI) to the use of water sources for human consumption. Ingeniería e Investigación, 30(3), 86-95. 